\title{
Editorial
}

\section{Dealing with the medical axis-of-power: the case of Japan}

\author{
NAOKI IKEGAMI* \\ Department of Health Policy and Management, School of Medicine, Keio University, Japan \\ JOHN CREIGHTON CAMPBELL \\ University of Michigan, USA and Department of Health Policy and Management, School of Medicine, \\ Keio University, Japan
}

In a previous editorial, William Hsiao (2007) stressed the importance of the political economy in shaping health policy decisions. The medical axis-ofpower, the close alliance of the health bureaucracy, hospitals directors, and physicians have so much power in China that, despite the wishes of the Politburo to provide affordable and accessible health care for all and reduce medical impoverishment, new resources may only go to 'a bloated bureaucracy and as higher income for the medical staff, more staffing, and reduced workload'. This possibility is by no means confined to China. Indeed, this criticism could also be directed to the recent increases in expenditures for the United Kingdom's National Health Service (NHS) (Maynard, 2007). However, Hsiao also stressed that reform cannot succeed without obtaining the cooperation of the medical axis-of-power.

In Japan, we believe that the policy decision to strictly limit the establishment of public hospitals, the government's proactive role in expanding coverage, and the control of virtually all medical spending via a universal fee schedule have been the three key factors in realizing universal coverage and containing costs to the lowest level among the G7 countries (Campbell and Ikegami, 1998; Ikegami and Campbell, 1999, 2004; OECD, 2006).

\section{Retarded development of hospitals and specialists}

Although Japan embarked on a policy of rapid Westernization from the latter half of the nineteenth century, little could be allocated to health care because the country was facing foreign aggression and internal discord: the limited resources had to be invested in defense and building industrial infrastructure.

*Correspondence to: Naoki Ikegami, Professor and Chair, Department of Health Policy \& Management, School of Medicine, Keio University, 35 Shinanomachi, Shinjuku-ku, Tokyo 160-8582, Japan. Email: nikegami@a5.keio.jp 
Thus, the government decided to concentrate on establishing a state-of-the-art medical school at Tokyo University, to which German physicians were invited as professors. Its graduates went on to establish faculties at other national universities as they later came to be established. The general population continued to receive care from pre-existing practitioners in Chinese traditional medicine, who, together with their sons as their successors, were unconditionally given a license to practice. However, there was a gradual transition to western medicine because new entrants had to graduate either from a university-level medical school or from a vocational-level school and then sit for the licensure examination.

As part of the westernization policy, the government did establish hospitals but they were restricted to those attached to universities, for the military forces, and for quarantining those with infectious diseases. ${ }^{1}$ Most hospitals were private, opened, and managed by physicians as an extension of their clinics. Because of the lack of trained physicians and well-equipped hospitals, a close and long-standing relationship developed between the professor and chair of the university clinical departments and their affiliated hospitals. Physicians tended to remain attached to their university clinical departments and to practice in the hospitals that were affiliated to each department. This hierarchical and closed structure of physicians retarded the development of professional specialist organizations.

After the defeat in World War II, the occupying forces tried to reform the system based on the American model with some limited success. The two-tiered system of medical education was abolished by upgrading or closing vocational-level schools and a national licensure examination was made mandatory for all students upon graduation. Post-war economic growth led to a major expansion of the delivery system, with the number of hospital beds increasing three-fold from 1954 to its peak in 1993. Two-thirds of the beds have continued to be in the private sector, mostly proprietary hospitals owned by physicians; the one-third referred to as 'public' include non-profit organizations such as the Red Cross as well as government-owned hospitals (mostly at the local level). There is mutual animosity between the two sectors, not without reason, because the latter has the lion's share of government subsidies and this has enabled them to invest in high-tech care.

Accordingly, the development of both specialists' organizations and hospital associations has been retarded in Japan. Lacking such powerful constituencies, the Health Policy Bureau within the Ministry has tended to play second fiddle to the Health Insurance Bureau. However, private-practice physicians,

1 The university hospitals have been under the jurisdiction of the Ministry of Education. The army and navy hospitals were turned over to the Health Ministry after the defeat in World War II, as were most of the tuberculosis hospitals built for the war effort. The infectious disease hospitals formed the nucleus of the present local government hospitals. 
who do not practice in hospitals, have been well organized under the Japan Medical Association (JMA). The JMA has managed to maintain its paramount position in organized medicine, despite the fact that the number of hospital-based physicians has increased to twice that of those who are office-based. As a result, resources have been prioritized to services provided in primary care settings, inhibiting the proliferation of high-tech, resourceintensive medicine.

\section{Incremental development of social health insurance (SHI)}

The basis of the current SHI started with legislation of the Health Insurance Act in 1922. It initially covered only blue-collar workers, representing only $3 \%$ of the population. The motives lay in pre-empting labour unrest and improving industrial productivity. These nationalistic goals prevailed over the opposition from all the parties directly concerned: employers, as it increased labour costs; employees, as workers had to partly finance their compensation that had previously been wholly funded by employers; and physicians, as they received lower fees. The unusual feature of this scheme was that blue-collar workers in small firms were covered at the same time as large-firm employees. The reason was not political: it may only have been simply bureaucratic in that small-firm employees had been covered by the same Worker's Compensation system as workers in large firms. Since small firms did not have the management capability or sufficiently large pools to manage their own system, the government had to provide health insurance for them directly; and this was the origin of the Government-managed Health Insurance (GMHI).

This role of the government as one among a variety of health insurance carriers, rather than just as a coordinator of insurance plans or the sole insurer, is the most distinctive element of Japan's health insurance system even today. In the postwar period it led to the Health Ministry taking the lead among insurers, rather than the associations of large firms or of municipal governments, for two reasons. First, as the population covered expanded to white-collar workers, the proportion insured by the GMHI came to nearly one-third, by far the largest plan in Japan. Second, compared to those working in large firms or the public sector, the income level of those employed in smaller companies was lower. Thus, in order to level the premium rates among the employment-based plans, the government finances $14 \%$ of the GMHI benefit expenditures from general revenues. Since this subsidized rate is fixed, in order to contain expenditures from general revenues the Ministry has an incentive to contain total GMHI expenditure. And since GMHI expenditure is largely determined by how the fee schedule (which is applied to all doctors and all hospitals) is revised, and the fee schedule is universally applied to all plans, this means that the government must contain total, and not just GMHI, health expenditures. 


\section{Expanding coverage}

The development of SHI can be divided into four periods: in the first and second, the covered population expanded, and, in the third and fourth, the differences in benefits gradually decreased. In the first period, the driving force came from the military who were concerned about the physical condition of draftees, and, by extension, of women who would be future mothers as the war with China intensified in the 1930s. ${ }^{2}$ In particular, they wished to improve the health status of the population in rural villages, where the majority lived, by extending coverage and by developing health care facilities. Their efforts were successful to the extent that, at its peak in $1943,70 \%$ of the population was covered. In the second period, from 1945 to 1961, when after the chaos of post World War II had subsided, the major political parties vied to establish a welfare state. The Health Ministry increased subsidies to Citizens' Health Insurance (CHI) for the self-employed, managed by municipalities. The subsidies varied according to the income level of the community. Thus, instead of subsidizing the poor as individuals, the government subsidized the CHI plans that insured those with low income. ${ }^{3}$ In 1961, when the last municipalities established their CHI programmes, universal coverage was achieved.

The third stage occurred from 1961 to 1982 when differences in benefits were decreased by increasing subsidies to CHI. This period culminated in 1973, when the co-insurance rate came to be waived entirely for the elderly (those 70 years and over) and lowered from $50 \%$ to $30 \%$ in the $\mathrm{CHI}$ and for dependents of employee-based plans. In the same year, co-insurance came to be waived for amounts exceeding 30,000 Yen per month in all plans. However, 1973 was the year when economic growth slowed as a result of the 'oil shock'. At the same time, health care expenditure, especially for the elderly, increased more than predicted and doubled by 1980. Many hospitals became de facto nursing homes providing long-term care, an unforeseen result of 'free' medical care for the elderly.

This set the stage for the last period, 1982 until today: benefits now became more equal by making them less generous to those who had been previously favoured. Legislation passed in 1982 led to the introduction of a $10 \%$ coinsurance for employees, and a small token payment for every ambulatory visit and for every day of hospitalization for the elderly. For employees, the rate increased to $20 \%$ in 1997 and to $30 \%$ in 2003. These increases did not reduce utilization of outpatient care, but they did decrease benefit expenditures (Cabinet Office, 2005). For the elderly, the flat rate gradually increased, and in 2003 , changed to an across-the-board $10 \%$ co-insurance rate. In 2003, the

2 Pressure from the army led to the establishment of the Ministry of Health and Welfare in 1938 and the transferal of the GMHI and the public health bureau from the Ministry of Interior.

3 This might appear to be giving subsidies to the rich. However, despite these subsidies, those with high incomes who live in a low-income community would have to pay a higher proportion of their income as premiums, in comparison to those who live in a high-income community. 
co-insurance rate for the elderly with income above that of the average employee increased to 20\%, and in 2006, to 30\% (Ikegami, 2006).

\section{The paramount role of the fee schedule}

The fee schedule plays a key role in linking the financing and delivery systems by serving as the valve that controls the money flowing from all insurance plans to all providers. It has maintained equity by making the benefit package essentially the same for all insurance plans, contained costs by restricting other sources of revenue to providers, and reduced administrative costs. Services, drugs and devices not listed in the fee schedule cannot be provided in combination with those that are covered during the course of the same treatment. Should they be provided, then all costs, and not just those of the uncovered services, must be paid out-ofpocket, with the exception of the services listed in the 'Specified Medical Costs'. These mainly consist of extra-billing for hospital rooms with more amenities and new technology still under development (Ikegami, 2006).

Fees and prices are uniform throughout Japan and, in principle, are the same for university hospitals and clinics, and with no adjustments for differences in local level of wages or cost of living. While this may seem to be unfair, it has contributed to a more equitable geographical distribution of services because the higher wages that health care workers demand in large, urban medical centers are compensated by the fact that physicians are willing to accept lower remunerations for the professional satisfaction of practicing in urban settings. On the other hand, workers in rural or small hospitals, or clinics, are willing to work at lower wages, but the physicians would demand higher salaries. Thus, the fee schedule is structured so as to favor an egalitarian provision of health care at the cost of specialists and urban medical centers.

There are three steps in the revision of the fee schedule made every two years. First, at the macro level, the cabinet decides on the global rate of change, with the Ministry of Finance demanding a decrease, the JMA lobbying for an increase, and the Health Ministry's Health Insurance Bureau playing a key role by providing data and technical expertise. Second, the price of drugs set by the payment system is revised primarily according to the results of a market-price survey. Third, service fees are individually revised within the budgetary limits set by the first two steps - not by applying a global revision rate across-the-board as a conversion factor. Thus, by increasing, or more likely, decreasing individual fees, the Health Ministry is able to micro-manage physician practice patterns. For example, in order to discourage physicians from dispensing medicines, fees are increased if the physician writes prescriptions for outside pharmacies. Fees have also been cut to reflect reductions in manufacturing and processing costs. For example, in the 2002 fee schedule revision, the fee for a head MRI (Magnetic Resonance Imaging) was reduced from 16,600 Yen (\$138) to 
11,400 Yen (\$95). Such examples of containing costs via micro-management of the fee schedule have been multiplied many times and have contained costs due to the expanded use of high-tech equipment. Note that despite such cuts in fees for MRI imaging, which have also been made in the past, Japan has the highest per capita number of MRI in the world (OECD, 2006). One reason is that the fee cuts have spurred the development of low-priced types of MRI.

\section{Lessons from the Japanese system}

Some health policy specialists may see the situation in Japan as too idiosyncratic to be of any value. For developing countries that have a goal of developing social health insurance (Hsiao and Shaw, 2007), the message may be that they have missed the boat: action should have been taken when the medical axis-of-power was not so entrenched, or the original sin may have been to invest their limited resources in building urban hospitals and establishing too many medical schools. However, although time obviously cannot be turned back, they could learn from the Japanese experience (Ikegami, 2007). First, it takes political will to achieve universal coverage and equity. The Japanese government was able to leverage its contribution from general revenues to initially expand coverage, then to decrease differences among SHI plans, and, currently, to contain costs. But the achievement of these goals should not be regarded as a natural consequence of the hybrid form of financing. It required the government's sustained commitment to improving equity and containing costs to within the constraints imposed by the budget. Second, when negotiating fees with providers, the rules of the game must be constantly rewritten by government technocrats because physicians can quickly interpret them to their advantage. These two points reemphasize the importance of the political economy in shaping health policy decisions. Japan was also fortunate in that there were no pro-market proponents in the health policy arena until recently, thus allowing actors to make decisions based on their intuition and courage, as the Health Vice-Minister and top bureaucrat Kuroki once remarked (Nihon Ijishinpou, 1993). Although pro-market proponents may renew their offensive to 'reform' the SHI system (Ikegami, 2006), it will be difficult for them to co-opt high-tech hospitals and specialists as they remain divided. This reemphasizes the importance of the medical axis-of-power, or its relative weakness, in forming health policy.

\section{References}

Cabinet Office (2005), Report on the Evaluation of Structural Reforms: Health Care Reform, Tokyo: Cabinet Office.

Campbell, J.C. and N. Ikegami (1998), The Art of Balance in Health Policy - Maintaining Japan's Low-cost, Egalitarian System, Cambridge: Cambridge University Press. 
Hsiao, W.C. and R.P. Shaw (2007), WBI Development Studies: Social Health Insurance for Developing Nations, Washington, DC: World Bank.

Hsiao, W.C. (2007), 'The political economy of Chinese health reform', Health Economics, Policy and Law, 2(3): 241-249.

Ikegami, N. (2006), 'Should providers be allowed to extra bill for uncovered services? Debate, resolution and sequel in Japan', Journal of Health Politics, Policy and Law, 31(6): 1129-1149.

Ikegami, N. (2007), 'Workshop on Japanese health care and implications for social health insurance in Egypt', http://web.worldbank.org/WBSITE/EXTERNAL/COUNTRIES/ MENAEXT/EGYPTEXTN/0, contentMDK:21264535 menuPK:2099399 pagePK:640 27988 piPK:64027986 theSitePK:256307,00.html

Ikegami, N. and J.C. Campbell (1999), 'Health care reform in Japan: the virtues of muddling through', Health Affairs, 18(3): 56-75.

Ikegami, N. and J.C. Campbell (2004), 'Japan's health care system: containing costs and attempting reform', Health Affairs, 23(3): 26-36.

Maynard, A. (2007), 'Is doctors' self-interest undermining the NHS?', British Medical Journal, 334: 234.

Nihon, Ijishinpou (1993), 'On the inauguration of the Institute of Health Economics and Policy', Quote from greetings by Vice-Minister Kuroki, Nihon Ijishinpou, 3604: 107.

OECD (2006), 'OECD Health Data 2006', CD-ROM. 